\title{
Evaluation of $R A D 51 C$ as cancer susceptibility gene in a large breast-ovarian cancer patient population referred for genetic testing
}

\author{
K. De Leeneer - M. Van Bockstal $\cdot$ S. De Brouwer $\cdot$ N. Swietek $\cdot$ P. Schietecatte \\ N. Sabbaghian $\cdot$ J. Van den Ende $\cdot$ S. Willocx $\cdot$ K. Storm $\cdot$ B. Blaumeiser $\cdot$ \\ C. J. Van Asperen · J. T. Wijnen · K. Leunen • E. Legius • G. Michils • \\ G. Matthijs • M. J. Blok • E. Gomez-Garcia $\cdot$ A. De Paepe $\cdot$ M. Tischkowitz \\ B. Poppe $\cdot$ K. Claes
}

Received: 13 January 2012/ Accepted: 13 February 2012

(C) Springer Science+Business Media, LLC. 2012

\begin{abstract}
Despite extensive analysis of the $B R C A 1$ and $B R C A 2$ genes, germline mutations are detected in $<20 \%$ of families with a presumed genetic predisposition for breast and ovarian cancer. Recent literature reported $R A D 51 C$ as a new breast cancer susceptibility gene. In this study, we report the analysis of 410 patients from 351 unrelated pedigrees. All were referred for genetic testing and we selected families with at least one reported case of ovarian cancer in which BRCAI\&2 mutations were previously ruled out. We analyzed the coding exons, intron-exons boundaries, and UTRs of RAD51C. Our mutation analysis did not reveal any unequivocal deleterious mutation. In total 12 unique sequence variations were identified of
\end{abstract}

Electronic supplementary material The online version of this article (doi:10.1007/s10549-012-1998-4) contains supplementary material, which is available to authorized users.

\footnotetext{
K. De Leeneer · M. Van Bockstal · S. De Brouwer · N. Swietek - P. Schietecatte · A. De Paepe · B. Poppe - K. Claes ( $\square)$ Center for Medical Genetics, Ghent University Hospital, Ghent, Belgium

e-mail: Kathleen.Claes@UGent.be
}

N. Sabbaghian · M. Tischkowitz

Program in Cancer Genetics, Departments of Oncology and Human Genetics, McGill University, Montreal, QC, Canada

J. Van den Ende $\cdot$ S. Willocx $\cdot$ K. Storm $\cdot$ B. Blaumeiser Center for Medical Genetics, University Hospital of Antwerp, Antwerp, Belgium

C. J. Van Asperen - J. T. Wijnen Department of Clinical Genetics, Leiden University Medical Center, Leiden, The Netherlands which two were novel. Our study and others suggest a low prevalence of $R A D 51 C$ mutations with an exception for some founder populations. This observation is in favor of the rare allele hypothesis in the debate over the nature of the genetic contribution to individual susceptibility to breast and ovarian cancer and further genome-wide studies in high risk families are warranted.

Keywords Hereditary breast and ovarian cancer . $R A D 51 C \cdot$ Germline mutations $\cdot$ BRCA1/2-negative

\section{Introduction}

Breast cancer is the most common type of cancer in women. It was estimated that 421,000 new breast cancer cases were diagnosed among European women in 2008,

\footnotetext{
K. Leunen

Department of Gynaecological Oncology, Catholic University of Leuven, Leuven, Belgium

E. Legius · G. Michils · G. Matthijs

Department of Human Genetics, Catholic University of Leuven,

Leuven, Belgium

M. J. Blok · E. Gomez-Garcia

Department of Clinical Genetics, Maastricht University Medical, Maastricht, The Netherlands

M. Tischkowitz

Department of Medical Genetics, University of Cambridge,

Cambridge, UK
} 
accounting for $28 \%$ of all new cancer cases [1]. Approximately $5 \%$ of all breast cancer cases can be attributed to germline mutations in BRCA1 and BRCA2, two tumor suppressor genes involved in maintaining genome integrity [2]. As numerous genetic linkage studies failed to identify additional high risk genes, it has been hypothesized that the remaining breast cancer clustering among families might not be explained simply by inheritance of variants in additional major high risk breast cancer susceptibility genes. Chance clustering and shared environmental and lifestyle factors may account for part of the familial breast cancer cases. However, twin studies have shown that the breast cancer risk for unaffected monozygotic twins with a co-twin diagnosed with breast cancer is higher compared to the risk for dizygotic twins. This strongly suggests that a significant proportion of the remaining familial breast cancer risk is likely due to genetic factors [3, 4].

As BRCA1 and BRCA2 are involved in DNA repair, and heterozygous mutations in DNA repair genes such as $A T M$ and TP53 have been associated with an increased breast cancer risk, most candidate gene approaches focused on genes involved in DNA repair. Thus far, this candidate gene approach has led to the identification of moderate risk breast cancer genes (CHEK2, ATM, BRIP1, PALB2, and $N B S 1)$. Variants in these intermediate penetrance genes are currently estimated to account for $5 \%$ of familial breast cancer risk [5].

The link between DNA repair and breast cancer susceptibility became even more intriguing after homozygous mutations in BRCA2 were found to be responsible for Fanconi Anaemia (FA) and BRCA2 was shown to be identical with FANCD1 [6]. No biallelic germline BRCAl mutations were reported in FA patients so far, but biallelic mutations in two other breast cancer susceptibility genes, PALB2 (FANCN) and BRIP1 (FANCJ), have been identified in FA patients, giving rise to complementation group FA-N and FA-J, respectively [7].

Recently, a fourth gene was found to be probably associated with both FA and breast cancer susceptibility. Vaz et al. [8] described an FA-like phenotype in a consanguineous Pakistani family with three affected children. These three patients exhibited various severe congenital anomalies, and a homozygous missense mutation in the $R A D 51 C$ gene was found to be causative. Because three genes (BRCA2, PALB2, BRIP1) were already known to be associated with both FA and breast cancer susceptibility, it seemed feasible to screen breast cancer families for monoallelic mutations in the $R A D 51 C$ gene. Meindl et al. [9] detected six monoallelic pathogenic mutations in RAD51C by screening 1,100 unrelated German women with gynecologic malignancies (breast and/or ovarian tumors). Strikingly, all six deleterious mutations were exclusively found within $480 \mathrm{BRCAl} / 2$ negative patients from families with at least one ovarian cancer case. No deleterious mutations were found in breast cancer only families [9]. These results support $R A D 51 C$ as a new breast/ovarian cancer susceptibility gene and according to its function and similarities with the other breast cancer susceptibility genes its role as tumor suppressor gene and caretaker has been stated. Recently, the gene coding for $R A D 51 D$, a protein that interacts with $R A D 51 C$, was discovered as an ovarian cancer susceptibility gene [10], but strikingly the association with breast cancer risk was statistically not significant in the British population.

In this study, we report the analysis of 410 patients from 351 unrelated pedigrees selected because they contained at least one reported case of ovarian cancer and in which $B R C A 1 \& 2$ mutations were previously ruled out. We analyzed the coding exons and intron-exon boundaries of $R A D 51 C$ in probands affected by breast, ovarian cancer or both and 24 unaffected cases with a first degree relative with ovarian cancer.

\section{Materials and methods}

\section{Patient population}

Hereditary breast and ovarian cancer families were recruited from cancer genetics clinics in Belgium, the Netherlands, and Canada. In all families, at least one individual with breast cancer and one individual with ovarian cancer (reported in a first, second or third degree relative) was present. Affected males and presymptomatic probands were included if there was an extensive family history for breast and ovarian cancer and no other relatives were available.

All probands consented to participate in the study which was approved by relevant Institutional Review Boards. In total 351 cases from unrelated families were screened (214 from Flanders, Belgium, 108 from the Netherlands, and 29 from Quebec, Canada). All patients were negative for BRCA1/BRCA2 mutations based on a mutation panel (for Ashkenazi Jewish and French Canadian cases in Canada) or full gene screening, including analysis of complete coding region and MLPA (Dutch and Belgian patients).

\section{Mutation analysis}

Genomic DNA from patient blood leukocytes was extracted according to standard methods. Analysis was performed in laboratories at two sites, Ghent and Montreal. In Ghent, primers were designed to cover the full coding sequence, $3^{\prime}$ and $5^{\prime}$ UTR and intron-exon boundaries encompassing all nine exons of RAD51C. RAD51C primers used in Montreal were as described by Vas et al., except 
exon 2 and 6 (both were redesigned). In Montreal, 25/29 families were analyzed by direct Sanger sequencing and $4 / 29$ by High resolution melting (HRM) followed by Sanger sequencing of the aberrant melting curves. In Ghent, 381 patients were analyzed by HRM on the 96-well or 384-well Lightscanner instrument (Idaho Technology) followed by sequencing of the fragments with aberrant melting curves. M13-tails were fused to the primers to simplify the sequencing process afterward. Primer sequences are available in Supplemental Table 1A and 1B. Detailed methods, including details of primers are provided in the Supplementary information (Supplementary Text).

Disease-causing potential of identified sequence variants was assessed using the Alamut 2.0 (interactive biosoftware) program. This software includes splicing predictions based on different algorithms (SpliceSiteFinder, MaxEntScan, NNSPLICE, GeneSplicer) and automated access to web-based variant scoring methods (PolyPhen, SIFT, Align-GVGD) for missense variants.

\section{Results}

We successfully analyzed the complete coding region and splice sites of $R A D 51 C$ in 351 unrelated probands with a family history for both breast and ovarian cancer. No unequivocal deleterious $R A D 51 C$ mutation was identified in our study population. In total our mutation analysis revealed 12 unique sequence variations of which two have to our knowledge never been reported before. An overview of all detected variants is given in Table 1.

$R A D 51 C$ c. $-78 \mathrm{~T}>\mathrm{C}$ ( $5^{\prime}$ flanking) and RAD51C c.$36 \mathrm{~A}>\mathrm{G}\left(5^{\prime}\right.$ UTR) have not been described before and are considered as variants of unknown clinical significance. These two variants are not predicted to alter splicing by in silico tools; hence, no further investigations were performed. Four of the remaining detected variants are not listed in dbSNP 132, but were previously described in literature. We identified the intronic variant $R A D 51 C$ c.572$17 \mathrm{G}>\mathrm{T}$ only once but it was previously reported by Romero et al. [11] in four breast cancer only families.

Two missense variants $R A D 51 C$ c.506T $>C$ (p.Val169Ala) and c.790G $>$ A (p.Gly264Ser) were previously reported by Meindl et al. [9] and functional studies suggest that none of these variants is clinically important. We identified $R A D 51 C$ c.506T $>$ C (p.Val169Ala) only once and RAD51C c.790 $\mathrm{G}>\mathrm{A}$ (p.Gly264Ser) in four index patients from breast and ovarian cancer families. The recurrence of RAD51C c.790 $\mathrm{G}>\mathrm{A}$ (p.Gly264Ser) among breast and ovarian cancer cases is in agreement with previous studies. Significant over-representation of p.Gly264Ser was found previously by Meindl et al. among breast and ovarian cancer families and in an unselected ovarian cancer cohort by Thompson et al. [9, 12].
In addition, several frequent SNPs were identified: $R A D 51 C$ c. $-26 \mathrm{C}>\mathrm{T}$ (rs12946397), c. $-54 \mathrm{C}>\mathrm{G}$ (rs28363298), c.904+ 34T $>\mathrm{C} \quad(\mathrm{rs} 28363318), \quad$ c.376G $>\mathrm{A} \quad$ (p.Ala126Thr) (rs61758 784), c.859A $>$ G (p.Thr287Ala) (rs28363317) and c. $* 25 C>G$ (rs28363336). Most of these SNPs are common in the Western population and were therefore identified in several other studies $[11,13,14]$. For none of these SNPs in silico predictions pointed in the direction of possible truncation of the protein function so no further prevalence or functional studies were performed.

\section{Discussion}

In this study, we evaluated the prevalence of $R A D 51 C$ germline mutations in 351 families with a family history for both breast and ovarian cancer but no unequivocal pathogenic mutation could be identified. In the initial report stating $R A D 51 C$ as a breast and ovarian cancer susceptibility gene [9], the coding sequence of RAD51C was analyzed in 1,100 index cases of German families with gynecological malignancies. Strikingly, the six monoallelic pathogenic mutations identified were detected exclusively in a subgroup of 480 families, where both ovarian and breast cancer was present. This resulted in a prevalence of $0.5 \%$ in the studied breast/ovarian cancer population compared to $1.3 \%$ prevalence in families, where both breast and ovarian cancer are present. Besides the initial study, we found 11 additional reports in the literature investigating the prevalence of $R A D 51 C$ mutations and six of them were negative [11-21]. In these 11 studies, the complete coding and splice site region of $R A D 51 C$ was investigated in 3.382 patients and in total nine $(0.3 \%)$ unequivocal deleterious $R A D 51 C$ mutations were identified. This overall prevalence is in the same range as the initial study but when families are subdivided in subgroups of patients with a family history for both breast and ovarian cancer the prevalence of $R A D 51 C$ mutations remains similar $(0.5 \%$ (5/966)). The additional four mutations were detected in ovarian cancer patients with or without a family history for the disease. There may be a founder effect for RAD51C mutations in the European Nordic countries, seven out of the nine patients carrying a RAD51C mutation are of a Swedish or Finnish descent, an observation that may distort the overall prevalence numbers. However, further investigations will be necessary since different $R A D 51 C$ mutations were detected among the Finnish and Swedish population and the increased prevalence may therefore be coincidental. Furthermore, the mutation prevalence may be underestimated in our calculations because we included only mutations with a clearly damaging impact on protein function. Some missense variants may prove to be damaging as well.

So far, no unequivocal pathogenic mutations have been identified in unselected breast cancer cases or breast cancer 


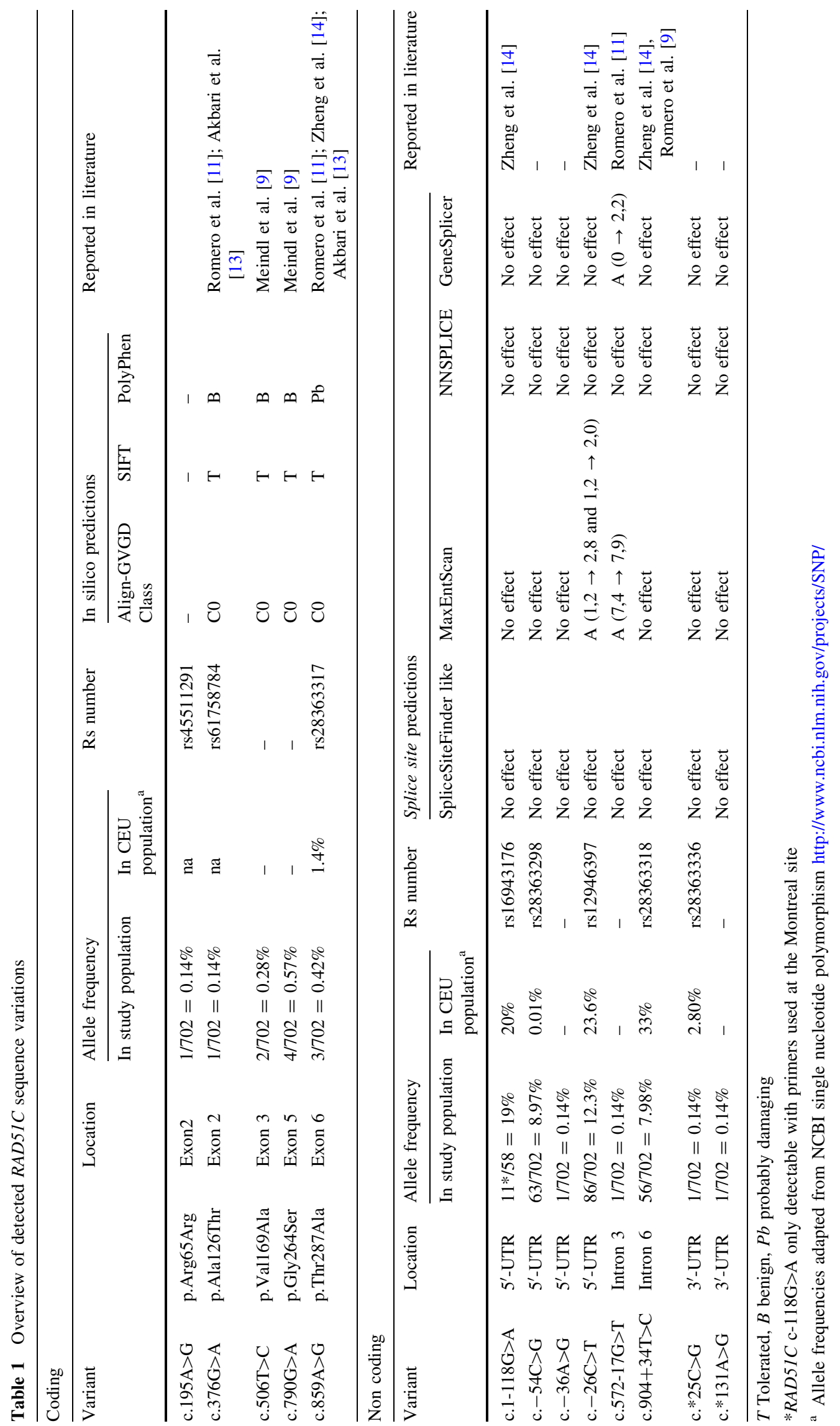


Table 2 Total patient population screened for $R A D 51 C$ mutations in this study

$O C$ ovarian cancer patient

Table 3 Overview of phenotypic characteristics of families with $R A D 51 C$ mutations

${ }^{\text {a }}$ Pelttari et al. [16]

b Romero et al. [11]

c Vuorela et al. [18]

d Thompson et al. [12]

e Walsh et al. [21]

${ }^{\mathrm{f}}$ Meindl et al. [9]

\begin{tabular}{lcllrr}
\hline & TOTAL & $\begin{array}{l}\text { 4 OC in } \\
\text { family }\end{array}$ & $\begin{array}{l}\text { 3 OC in } \\
\text { family }\end{array}$ & $\begin{array}{l}\text { 2 OC in } \\
\text { family }\end{array}$ & $\begin{array}{l}\text { 1 OC in } \\
\text { family }\end{array}$ \\
\hline No. of ovarian cancer probands & 88 & 4 & 0 & 27 & 57 \\
No. of breast/ovarian cancer probands & 36 & 1 & 1 & 7 & 27 \\
No. of breast cancer probands & 203 & 1 & 1 & 31 & 170 \\
No. of presymptomatic probands & 24 & 1 & 1 & 5 & 17 \\
Total probands screened & 351 & 7 & 3 & 70 & 271 \\
$R$ RD51C mutations identified & 0 & 0 & 0 & 0 & 0 \\
\hline
\end{tabular}

\begin{tabular}{|c|c|c|c|c|c|c|}
\hline$R A D 51 C$ mutations identified & $\begin{array}{l}4 \text { OC in } \\
\text { family }\end{array}$ & $\begin{array}{l}3 \text { OC in } \\
\text { family }\end{array}$ & $\begin{array}{l}2 \mathrm{OC} \text { in } \\
\text { family }\end{array}$ & $\begin{array}{l}1 \mathrm{OC} \text { in } \\
\text { family }\end{array}$ & $\begin{array}{l}\text { family } \\
\text { history } \\
\text { unknown }\end{array}$ & unselected \\
\hline $\begin{array}{l}\text { No. of ovarian cancer } \\
\text { probands }\end{array}$ & 0 & 0 & $2^{\mathrm{a}, \mathrm{d}}$ & $3^{\mathrm{a}, \mathrm{f}}$ & $1^{\mathrm{c}}$ & $7^{\mathrm{a}, \mathrm{d}, \mathrm{e}}$ \\
\hline $\begin{array}{l}\text { No. of breast/ovarian cancer } \\
\text { probands }\end{array}$ & 0 & $1^{\mathrm{d}}$ & 0 & 0 & 0 & 0 \\
\hline No. of breast cancer probands & $1^{\mathrm{c}}$ & 0 & $2^{b, f}$ & $3^{\mathrm{a}, \mathrm{f}}$ & 0 & 0 \\
\hline Total $R A D 51 C$ mutations identified & 1 & 1 & 4 & 6 & 1 & 7 \\
\hline
\end{tabular}

only families. However, several putative pathogenic missense variants have been identified in breast cancer only families. We did not include these two subgroups in our study (Table 2). Furthermore, the identification of RAD51C mutations in families with a mixed phenotype and (unselected) ovarian cancer cases with a family history for ovarian cancer only, points rather toward a role as ovarian cancer susceptibility gene. Further evidence on the link between $R A D 51 C$ and ovarian cancer might be the recent discovery of RAD51C's direct interaction partner RAD51D as an ovarian cancer susceptibility gene [10]. Loveday et al., found a significant higher prevalence of $R A D 51 D$ mutations in families with more than one case of ovarian cancer. In contrast, the majority of RAD51C mutations are detected in families with only 1 case of ovarian cancer, a subgroup largely covered in our study population (271 patients). An overview of the prevalence of previously reported $R A D 51 C$ mutations in different patient subgroups is given in Table 3. Due to the low prevalence of RAD51C mutations and the lack of information on the number of ovarian cancer patients present in all investigated families in literature, it remains difficult to come to similar conclusions as for $R A D 51 D$, but the link between $R A D 51 C$ and ovarian cancer warrants further investigations.

It is clinically important to identify patients with $R A D 51 C$ germline mutations, patients and their family members will benefit from appropriate genetic counseling. Furthermore, carcinomas with $R A D 51 C$ mutations are likely to be deficient in homologous recombination and thereby susceptible to PARP inhibitors. We and others failed to detect germline $B R C A 1 \& 2$ or $R A D 51 C$ mutations in significant numbers of families with a clear autosomal dominant inheritance pattern of breast cancer, this supports the concept of the existence of additional breast cancer susceptibility genes and this is currently being investigated by new sequencing approaches. A whole exome/genome approach might help finding some missing pieces of the puzzle.

In conclusion, we were unable to confirm the role of $R A D 51 C$ germline mutations in families with a history for both breast and ovarian cancer. Our study and others suggest a low prevalence of $R A D 51 C$ mutations with an exception for some founder populations. Further genome-wide studies in selected high risk families will allow the identification of rare high penetrant alleles contributing to individual genetic susceptibility to breast and ovarian cancer.

Acknowledgments This research was supported by grant G.A044.10 from the Fund for Scientific Research Flanders (FWO), by GOA grant BOF10/GOA/019 (Ghent University). "Emmanuel van der Schueren" grant from the "Vlaamse Liga tegen Kanker" and by the Quebec Ministry of Economic Development, Innovation and Export Trade (MDEIE). Furthermore, the authors would like to thank Yvonne Detisch for her help with collecting the clinical information of the families of Maastricht.

Conflict of interest The authors have no conflict of interest.

\section{References}

1. Ferlay J, Parkin DM, Steliarova-Foucher E (2010) Estimates of cancer incidence and mortality in Europe in 2008. Eur J Cancer 46(4):765-781

2. O'Donovan PJ, Livingston DM (2010) BRCA1 and BRCA2: breast/ovarian cancer susceptibility gene products and participants in DNA double-strand break repair. Carcinogenesis 31(6):961-967

3. Ahlbom A, Lichtenstein P, Malmstrom H, Feychting $M$, Hemminki K, Pedersen NL (1997) Cancer in twins: genetic and nongenetic familial risk factors. J Natl Cancer Inst 89(4):287-293 
4. Mack TM, Hamilton AS, Press MF, Diep A, Rappaport EB (2002) Heritable breast cancer in twins. Br J Cancer 87(3): 294-300

5. Stratton MR, Rahman N (2008) The emerging landscape of breast cancer susceptibility. Nat Genet 40(1):17-22

6. Howlett NG, Taniguchi T, Olson S, Cox B, Waisfisz Q, De DieSmulders C, Persky N, Grompe M, Joenje H, Pals G et al (2002) Biallelic inactivation of BRCA2 in Fanconi anemia. Science 297(5581):606-609

7. Levy-Lahad E (2010) Fanconi anemia and breast cancer susceptibility meet again. Nat Genet 42(5):368-369

8. Vaz F, Hanenberg H, Schuster B, Barker K, Wiek C, Erven V, Neveling K, Endt D, Kesterton I, Autore F et al (2010) Mutation of the RAD51C gene in a Fanconi anemia-like disorder. Nat Genet 42(5):406-409

9. Meindl A, Hellebrand H, Wiek C, Erven V, Wappenschmidt B, Niederacher D, Freund M, Lichtner P, Hartmann L, Schaal H et al (2010) Germline mutations in breast and ovarian cancer pedigrees establish RAD51C as a human cancer susceptibility gene. Nat Genet 42(5):410-414

10. Loveday C, Turnbull C, Ramsay E, Hughes D, Ruark E, Frankum JR, Bowden G, Kalmyrzaev B, Warren-Perry M, Snape K et al (2011) Germline mutations in RAD51D confer susceptibility to ovarian cancer. Nat Genet 43(9):879-882

11. Romero A, Perez-Segura P, Tosar A, Garcia-Saenz JA, DiazRubio E, Caldes T, de la Hoya M (2011) A HRM-based screening method detects RAD51C germ-line deleterious mutations in Spanish breast and ovarian cancer families. Breast Cancer Res Treat 129(3):939-946

12. Thompson ER, Boyle SE, Johnson J, Ryland GL, Sawyer S, Choong DY, Kconfab, Chenevix-Trench G, Trainer AH, Lindeman GJ et al. (2011) Analysis of RAD51C germline mutations in high-risk breast and ovarian cancer families and ovarian cancer patients. Human mutation 12(66):433-43

13. Akbari MR, Tonin P, Foulkes WD, Ghadirian P, Tischkowitz M, Narod SA (2010) RAD51C germline mutations in breast and ovarian cancer patients. Breast cancer research BCR 12(4):404
14. Zheng Y, Zhang J, Hope K, Niu Q, Huo D, Olopade OI (2010) Screening RAD51C nucleotide alterations in patients with a family history of breast and ovarian cancer. Breast Cancer Res Treat 124(3):857-861

15. Pang Z, Yao L, Zhang J, Ouyang T, Li J, Wang T, Fan Z, Fan T, Lin B, Xie Y (2011) RAD51C germline mutations in Chinese women with familial breast cancer. Breast Cancer Res Treat 129(3):1019-1020

16. Pelttari LM, Heikkinen $\mathrm{T}$, Thompson D, Kallioniemi A, Schleutker J, Holli K, Blomqvist C, Aittomaki K, Butzow R, Nevanlinna H (2011) RAD51C is a susceptibility gene for ovarian cancer. Hum Mol Genet 20(16):3278-3288

17. Silvestri V, Rizzolo P, Falchetti M, Zanna I, Masala G, Palli D, Ottini L (2011) Mutation screening of RAD51C in male breast cancer patients. Breast cancer research BCR 13(1):404

18. Vuorela M, Pylkas K, Hartikainen JM, Sundfeldt K, Lindblom A, von Wachenfeldt Wappling A, Haanpaa M, Puistola U, Rosengren A, Anttila M et al (2011) Further evidence for the contribution of the RAD51C gene in hereditary breast and ovarian cancer susceptibility. Breast Cancer Res Treat 130(3):1003-1010

19. Wong MW, Nordfors C, Mossman D, Pecenpetelovska G, AveryKiejda KA, Talseth-Palmer B, Bowden NA, Scott RJ (2011) BRIP1, PALB2, and RAD51C mutation analysis reveals their relative importance as genetic susceptibility factors for breast cancer. Breast Cancer Res Treat 127(3):853-859

20. Clague J, Wilhoite G, Adamson A, Bailis A, Weitzel JN, Neuhausen SL (2011) RAD51C germline mutations in breast and ovarian cancer cases from high-risk families. PLoS ONE 6(9): e25632

21. Walsh T, Casadei S, Lee MK, Pennil CC, Nord AS, Thornton AM, Roeb W, Agnew KJ, Stray SM, Wickramanayake A et al (2011) Mutations in 12 genes for inherited ovarian, fallopian tube, and peritoneal carcinoma identified by massively parallel sequencing. Proc Nat Acad Sci USA 108(44):18032-18037 